\title{
SUPPLEMENT
}

\section{Explanatory Remarks for 'Guidelines on Worksite Prevention of Low Back Pain': Measures by Type of Work}

\section{Handling of Heavy Objects}

\section{On 'Automation or reduction of manual handling tasks'}

There are originally two types of ergonomic approaches: one has been developed for the improvement of work posture while the other for the improvement of motion in handling heavy objects. They have a lot of common measures in practice, for example, adoption of work tables with lifting function, installation of monorail carrier system with hooked conveyors, and jack lifts.

\section{On 'Weight limit of the manual handling'}

The maximum muscle ability lasts very short, then the force diminishes as the time elapses. The maximum weight depends on holding duration, which is influenced by muscular strength.

Repetitive lifting of heavy objects requires more energy consumption, in consequence more load to respiratory and circulatory systems. Therefore, it is necessary to rearrange the time of operation and short break/rest.

In general, the lifting ability of the females is considered approximately 60 percent of that of the males.

\section{On 'Improvement of freight packaging and indication of} weight'

When hooks or the like are provided to objects concerned or they are packed for easy handling, it is necessary to minimize the distance between the gravitational center of the object and the worker.

Some objects are harder to handle than others due to their packaging in spite of the same weight. Some objects are heavier than they appear. Those objects may cause sudden workload to the back due to mismatched force or reaction from the objects, in consequence low back pain. Indication of the weight allows workers to know the actual weight before lifting or other motion with proper posture.

It is also necessary to help workers handle objects with proper posture by the indication of gravitational center if their weight is extremely unbalanced unlike their appearance.

\section{On 'Work posture and motion'}

(1) When lifting up an object from the floor, hold the object with squatting posture (Fig. I-a), with one leg a little ahead of the body, and with the knees bent, then lift it up by extending the knees. Avoid the back bending posture with the knees extended (Fig. I-b). That may not be applied to the case in which a person with some knee impairment lifts up relatively light objects.

(2) Twisting motion with holding heavy objects can often cause low back pain due to excessive workload to the back. The best way is to eliminate such operations involving twisting motion. The twist of the body should be minimized by arranging the height, allocation and layout of work tables if that is difficult.

\section{Operations at Accommodations for Handicapped Children or the Like}

\section{On 'Work posture and motion'}

a. When lifting up a person from the floor, hold the object with squatting posture (Fig. II-a), with one leg a little ahead of the body, and with the knees bent, then lift it up by extending the knees. Avoid the back bending posture with the knees extended (Fig. II-b).

b. When holding up a person in front of the holder's body, keep as close as possible (Fig. II-c). Try not to lift up the person beyond the height of the waist (Fig. II-d), nor to stretch or overstretch the back (Fig. II-e).

\section{On 'Work manual'}

Work manuals on operation at accommodations should be prepared in consideration of each work condition so as not to make them too general. They should be revised every 
time new devices or facilities are introduced or some of admitted children or the like, or the work methods are changed.

Operation at accommodations with awkward posture for long periods causes workload to the back. It is necessary to divide work clearly and manage the operation time properly, before preparing work manuals, in consideration of not doing more than one thing at the same time; such as writing daily report during operation, eating while serving meals.

\section{On 'Improvement of facilities and structures'}

It is desirable to improve the facilities and structures in terms of convenient use as well as safety and health aspects by asking advice of ergonomic or industrial hygiene specialists, and investigating beds, bathtubs, lavatories, bodywashing tables, care and living rooms, offices, nursing stations, kitchens, entrances, passages; floor materials and floor steps.

a

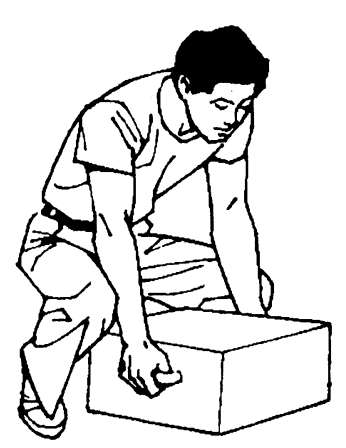

b

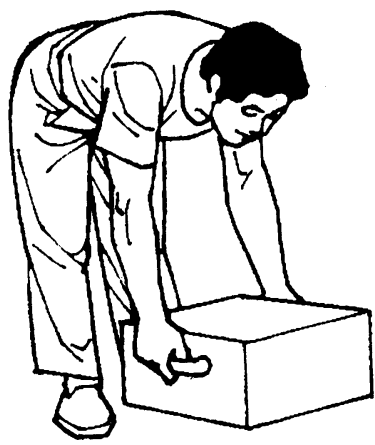

Fig. 1.

Beds should be equipped for easy move of admitted children or the like on, and be able to adjust the height. 'Proper related facilities and devices should be installed' means the installation of related facilities for operation at accommodations, for example, the introduction of work tables with sufficient space and chairs with backrest for desk work or meetings. 'Equipment or the like for operation at accommodations' means daily needs, bedding, medical instruments, care equipment, textbooks, toys and so on.

\section{Standing Operations with Significant Workload to Back}

\section{On 'Allocation of machinery'}

Improper allocation of machinery forces workers into back bending posture, or overstretching of muscle. It is known that such posture extremely increase internal pressure on intervertebral disks.

The use of footrest is one of the simplest way to adjust the height of work tables to workers' physical features.

\section{On 'Combination with other operations'}

Sitting posture loads more to the lumbar vertebra than standing posture. It is necessary to take account of workers with low back pain history if sitting posture is combined with standing posture.

\section{On 'Provision of chairs'}

Standing posture for long periods causes the fatigue of vertebra supporting muscles and lower-limb muscles as well as the increase of internal pressure on intervertebral disks. Muscle contraction and muscle fatigue can effectively be
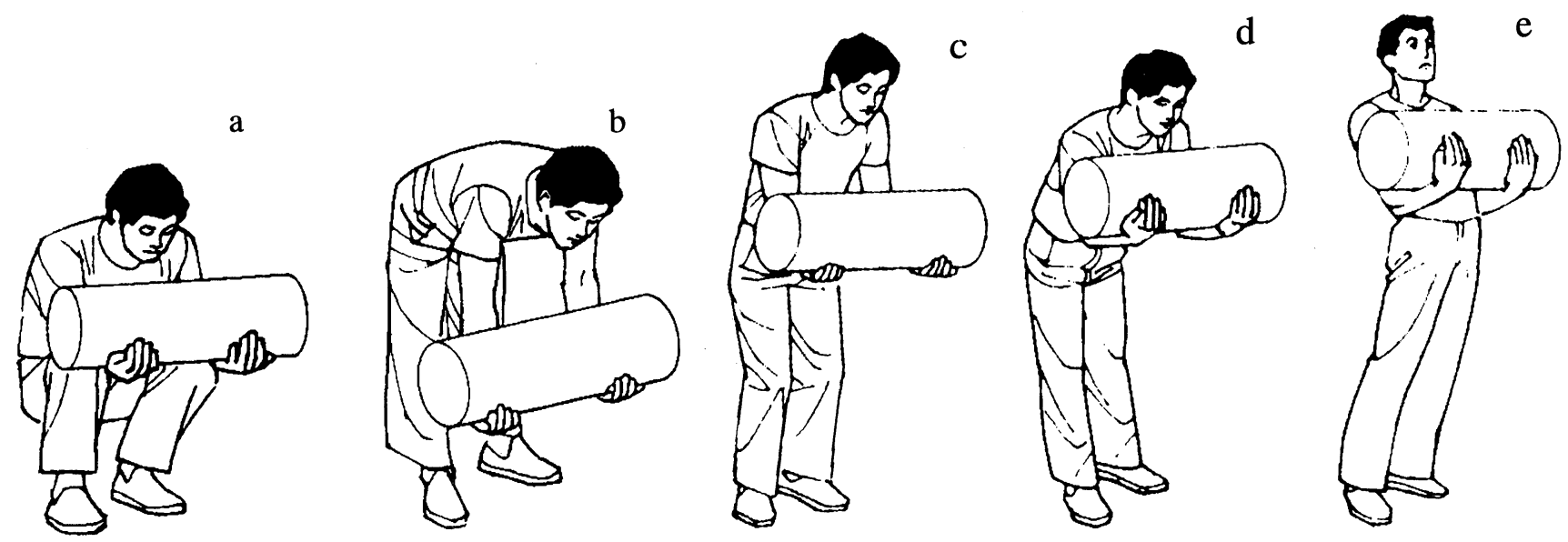

Fig. 2. 
relieved by sitting on a chair.

\section{On 'Use of footrests'}

Putting a foot on a footrest and then another at intervals is effective in prevention of low back pain. Footrest should have proper size, height and surface area, be stable and be made of appropriate materials.

\section{On 'Short break/rest'}

Short break/rest with knee-bending exercises is effective in better blood circulation in the lower limbs.

\section{Sitting Operations in a Chair or on the Floor with Significant Workload to Back}

\section{On 'Improvement of chairs'}

The pelvis revolves backward and natural curve of the lower back decreases when the thigh and the trunk are fixed at an angle of 90 degrees. And back muscles become tonic due to the forward shift of the body center of gravity. It is known that sitting posture causes higher internal pressure on intervertebral disks than standing posture. Improvement of chairs is important for changing such undesirable conditions.

The following are the conditions of desirable chairs in terms of prevention of back pain: chairs

a. with seat surface declining 14-24 degrees backward.

b. with backrest declining backward, (110-130 degrees to the floor).

c. with lumber support on the backrest. It is preferable that the top of the lumbar support be as the same height as the middle of the third and the fourth lumbar vertebrae of the worker.

In addition, chairs should, desirably, be able to adjust the following points in accordance with the body size of the worker: seat height and angle, and the backrest mobility back-and-forth or up-and-down. They should be stable, equipped with casters for position adjustment, and made of comfortable materials with good heat exchange.

\section{On 'Improvement of work tables'}

Devices and equipment on work tables should be appropriate size and height so as to keep operating area and visibility over them.

\section{On 'Work posture or the like'}

Sitting posture, free from fixing leg joints and knee joints, etc., causes less muscle fatigue than standing posture for the whole body. Further, less contraction of lower limb muscles and less hydrostatic pressure to heart reduce interference in vein circulation.

It is suitable to desk work such as minute work and writing because of the stability of the upper body. It is, on the other hand, not suitable to operations involving repetitive motion of the body or requiring large force or moment.

Sitting posture for long periods can cause declining posture, relaxation of abdominal muscle, change in the natural curve of spine, or the pressure to thigh due to the fatigue of back muscles. It is necessary to make the posture declining backward by changing foot position or backrest angle or to stand up for extending knees at intervals in order to avoid such adverse effects.

\section{On 'Sitting operations on the floor'}

Sitting operations on the floor, involving forward-declining posture, causes stronger contraction of back muscles and excessive raise in internal pressure between intervertebral disks. Therefore, sitting operations on the floor should be avoided as far as possible.

Sitting operations on the floor is often seen among socalled 'craftsmen' or the like. It is recommendable to control the speed of work and take longer and more frequent 'short break/rest' for sitting operations on the floor.

\section{Commercial Vehicle Operations or the Like}

\section{On 'Improvement of seat or the like'}

Driving seats should be qualified in terms of body pressure distribution, seating posture, elasticity, backrest size and fitness, and holding for stable back support against acceleration or vibration. Sitting posture with erect upper body is more subject to whole body vibration than relaxed one, which results in raised muscle tonus and reflexes, and in reduced peripheral blood flow. It is said that vibration may decline the visual function such as the change in stimuli to sense of equilibrium and the delay in visual recognition. It is, therefore, desirable to improve the seat into dumping structure.

The internal pressure on intervertebral disks, which has a relationship to the development to low back pain, depends on the height of back support and the angle of backrest. As the angle of backrest increase, the pressure decreases. However, the operativity of steering wheel declines and the load of shoulder muscles increases over 130 degrees due to stretched elbow joints. Therefore, the appropriate angle of backrest ranges between approximately 110 and 120 degrees. 


\section{On 'Short break/rest'}

It is desirable that workers are provided with 'active rest,' i.e., light gymnastic exercises such as knee-bending out of the vehicle during the rest since short break/rest aims for the elimination of workload due to fixed work posture.

It is desirable to take longer 'short break/rest' for work with twisting posture backward such as forklift operation.

On 'Handling of heavy objects just after the vehicle driving'

It is not desirable to handling heavy objects immediately after driving for hours. That is because, during driving vehicles, temporal malfunction in muscle control system (ennui) may be caused by the interference of peripheral blood circulation due to fixed posture, elevated tonus of trunk muscles, the influence of vibration on the sense of equilibrium in the inner ear, or the like. Instead, it is necessary to handle heavy objects only after the short break/rest and warm-up exercises to eliminate malfunction in muscle control and the interference of peripheral blood circulation.

\section{Acknowledgment}

I would like to express my sincere thanks to the International Affairs Division, Japan Industrial Safety and
Health Association (JISHA) for its permitting us to publish the English version of "Guidelines on Worksite Prevention of Low Back Pain" in INDUSTRIAL HEALTH. JISHA originally translated into English the Japanese version of the guidelines, which were issued as Labour Standards Bureau Notification No. 547 on September 6, 1994.

I am deeply grateful to Mr. Ken-ichi Kamae, Industrial Health Division, Industrial Safety and Health Department, Ministry of Labor, for his enthusiastic efforts in further revising the English version. Mr. Kamae's editing of the guidelines were carried out during his stay at Harvard School of Public Health as a Master of Science student of Industrial Hygiene. Furthermore, the guidelines was improved by Dr. Theodore K. Courtney, M.S., CSP, Visiting Lecturer on Ergonomics, Harvard School of Public Health and Assistant Director, Liberty Mutual Research Center for Safety and Health, Boston, MA, USA. I would like to greatly acknowledge Dr. Courtney for his valuable assistance with the English translation.

I hope that the newly edited guidelines help prevent low back pain among workers worldwide.

Sohei Yamamoto, M.D.

Editor-in-Chief, Industrial Health

Director, National Institute of Industrial Health 


\section{Appendix 1}

Low Back Pain Medical Examination Questionnaire

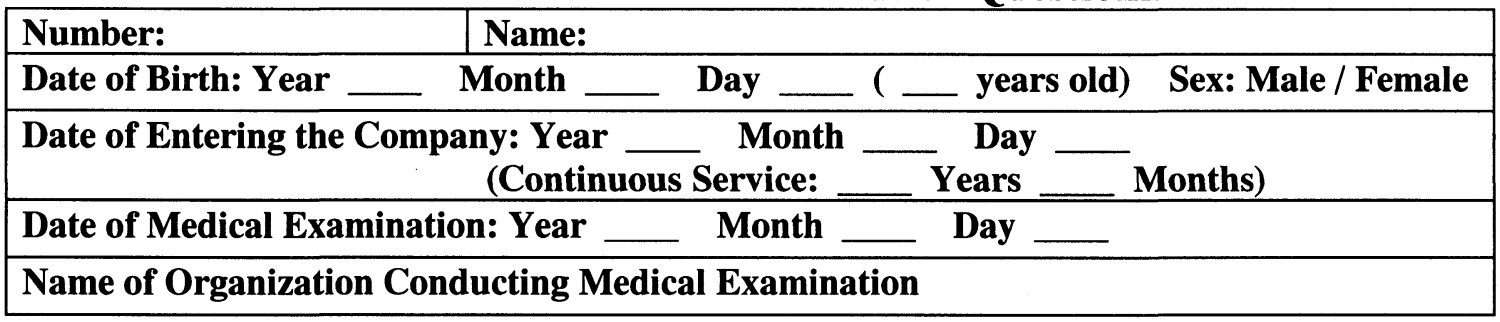

Please mark a slash for the choices and complete the underlined' blank for each of the following questions.

\section{Work History}

Before your current work assignment, have you ever done another type of work?
(1) No
(2) Yes (Type of Work )

\section{Past Diseases}

Have you ever suffered from a serious illness?

(1) No

(2) Yes (Name of the illness )

\section{Low Back Pain History}

If you answered (1) in Question 1, please proceed to Question 4.

(1) Have you ever suffered from low back pain?

(1) No

(2) Yes (First time was about Year _ Month _

(2) Where did you suffer from low back pain for the first time?

(1) In the workplace

(2) At home during daily living

(3) As a result of a traffic accident

(4) During sports

(5) Other

(3) How did you happen?

(2) Guddenly

When did it happen?

a. When you lifted something up, put it down, carried it, stepped aside of it, picked it up, push it, pulled it.

b. While working in a half-sitting posture

c. While working in a crouching posture

d. While keeping an unnatural posture

e. While doing standing work

f. While doing driving work

g. While doing care-giving work

h. In a cold place

i. When twisted the low back region

$\mathrm{j}$. When received a blow in the low back region

k. When falling on your behind
1. When falling from a height

$\mathrm{m}$. When turning over on the side

n. While washing the face

o. When sneezing

p. Other

(4) Treatment

(1) Did nothing

(2) Family (home) treatment

(3) Had a massage, acupuncture, etc.

(4) Had a medical examination and treatment at a medical organization

(5) What symptoms have occurred since then (including sciatica and numbness of lower limbs)?

(1) Occurred times

(2) The low back pain has remained since the first time

(3) Feel low back pain occasionally (when the seasons / weather changes occur, when tired, etc.)

(4) No low back pain since the first time

(5) Other

4. Present situation

(including low back stiffness, lassitude and dullness)

If you answered (1) in Questions 1-4, please proceed to Question 5.

(1) Do you have low back pain now?
(1) No
(2) Yes (including sometimes)

(2) Since assigned to current work, has low back pain recurred?

$\begin{array}{ll}\text { (1) No (2) Yes (sometimes) } & \text { No }\end{array}$

(3) Yes (often)

(3) Since assigned to current work, has low back pain become worse?
(1) No
(2) Yes

(4) Has low back pain occurred within the last one month?
(1) No
(2) Yes

(5) When do you feel pain in the lumber region?
(1) When turning over in sleep
(2) When waking up in the morning 
(3) When washing the face

(4) When starting to stand up or sit down

(5) When keeping standing

(6) When keeping half-sitting position

(7) When keeping crouching position

(8) When working in face-up position

(9) When lifting or holding heavy objects, or when holding person or moving while holding person

(10) When sitting in a chair or on the floor for a long time

(11) While driving

(12) While walking

(13) Other

(6) How strong is the current pain?

(1) Cannot work without taking rest sometimes

(2) Fairly strong but not necessary to take rest

(3) Feel light pain sometimes

(4) Feel dull pain in lumber region

(7) Do you feel pain, stiffness, dull pain and/or numbness in the lower limbs?

(1) No

(2) Yes (including cases of sometimes)

What type of pain is felt in the lower limbs (including stiffness, throbbing pain, dull pain, and lassitude)?

a. From buttock and thigh to knee

b. From buttock and thigh to foot

c. Numbness in the leg

d. Cannot give strength to leg and have difficulty in walking

(8) How has walking been affected?
(1) Possible to walk normally
(2) Pain, numbness or weakness occurs when walking
(3) When stopping walking and bending forward or crouching, the pain and numbness ease

(9) Does the symptom change?

(1) Worse when waking up in the morning or starting work; gradually getting better while moving

(2) Gets worse while moving

(3) Gets worse when coughing and sneezing

Is it influenced by weather?

a. Yes, related to weather

b. No, no relation

Does it change when you take a bath?

a. it gets better

b. No change

c. It gets worse

(10) Are you being treated for low back pain now?
(1) Yes
(2) No

\section{Work situation}

(1) Please describe current work. Have engaged in current work: Contents of the work: years

(2) What is your usual working locate?

(1) Outdoor work

(2) Work in narrow, unstable or slippery area

(3) Work accompanied by shaking, vibration or shock

(4) Work in cold place

(5) Other

(3) How is your most frequent working position?

(1) Sitting in a chair

(2) Sitting on the floor

(3) Half-sitting position

(4) Standing work

(5) Working with face-up

(6) Work requiring deep forward bending

(7) Work involving driving vehicles

(8) Other

(4) What objects are handled?

(1) Often handle objects of __ $\mathrm{kg} \sim \ldots \mathrm{kg}$ by myself

(2) Hardly ever handle heavy objects

(3) Mainly care-giving work

(5) What is the most frequent work format?

(1) Lifting work

(2) Work involving lowering things

(3) Cargo loading work

(4) Cargo unloading work

(5) Carrying work

(6) Moving work

(7) Pushing or pulling work

(8) Care-giving work

(9) Other

(6) Do you perform pre-work exercises?
(1) Yes (periodically)
(2) Yes (sometimes)
(3) No

(7) Do you exercise in your daily life?

(1) Yes

(2) No

Type of Exercise:

How often: hour(s) $\times$ time(s) per week

\section{Observations and Diagnosis}

by Dr. (Seal) 
Appendix 2

Low Back Pain Medical Examination Personal Record

\begin{tabular}{|c|c|c|}
\hline Number: & Name: & \\
\hline Date of Birth: Year & _ Day __ $(\ldots$ years old $)$ & Sex: Male / Female \\
\hline \multicolumn{3}{|c|}{$\begin{array}{c}\begin{array}{c}\text { Date of Entering the Company: Year } \\
\text { (Continuous Service: }\end{array}-\text { Years }- \text { Month }- \text { Months) }\end{array}$} \\
\hline Date of Medical Examina & _ Month _ _ Day & \\
\hline
\end{tabular}

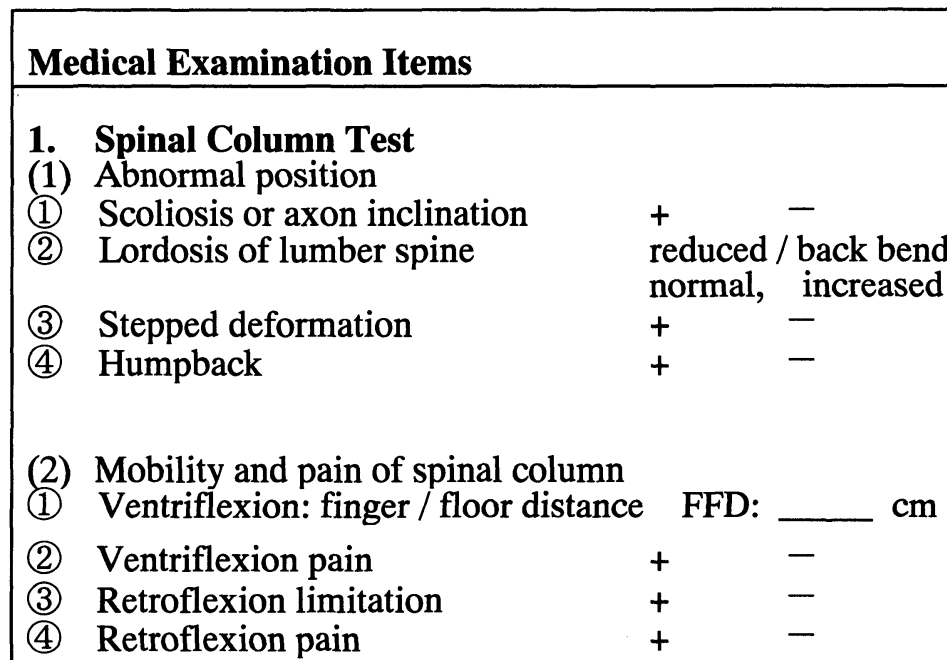

(3) Muscular tonus

(1) Increased or indurated paraspinal muscular tonus:

left: + - right: + -

(4) Tenderness, tapping ache (Mark the following item(s))

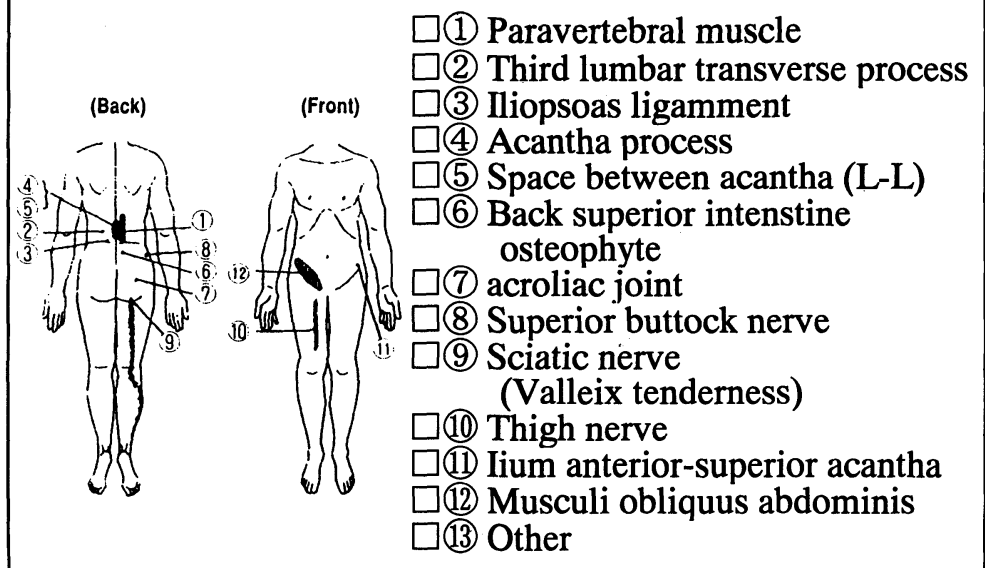

(5) Kemp symptoms $+\quad-$

(6) Latexion limitation +-

(7) Latexion pain

(2) Increased tonus in muscular obliquus abdominis left: $+\quad-$ right: +-

(3) Muscle contracture

* Musculi iliopsoas

left: $+\quad-$ right: +-

* Rectus femoris left: $+\quad-$ right: +-

* Hamstring group left: +- right: $+\quad-$

* Musculi triceps surae left: $+\quad-$ right: +- 
2. Neurological Test

(1) Tension sign

(1) Leg SLR test

left: $+-\left(\_\right.$degree $)$

right: $+-(\square$ degree $)$

(2) Thigh nerve dilation test

left: +- right: +-

(2) Deep tendon reflex

(1) Patella tendon reflex (PTR)

left: disappear reduced normal increased right: disappear reduced normal increased

(2) Achilles tendon reflex (ATR)

left: disappear reduced normal increased right: disappear reduced normal increased

\section{Spinal column functional test}

(Clause/Weber Test)

(1) Abdominal muscle (Raising upper body)

1) Muscle strength normal reduced

2) Muscle durability normal reduced

(2) Dorsolumbar muscle
1) Muscle strength
normal
reduced

2) Muscle durability

normal

reduced
(3) Well leg raising test (WLR)<smiles>[CH-][CH2+]</smiles>

(3) Leg perception test

(1) Perception disturbance

left: +- right: +-

(2) Region

(4) Muscle strength

(1) Knee jerk distention

left: normal reduced right: normal reduced

(2) Toe dorsiflexion

left: normal reduced right: normal reduced

(3) Toe subreflexion

left: normal reduced right: normal reduced

(4) Abdominal muscle normal reduced

(5) Muscular atropy
(1) Musculi gluteus
left: + right: +-
(2) Musculi tibialis anterior left: + - right: + -
(3) Musculi triceps surae left: +- right: +-

(6) Psychogenic factors
(1) Hoover Test +
(2) Burns Test + -
(3) Flip Test + -

\section{Lumbar X-ray test (standing position, 1/4)}
(1) No positive findings
(2) Osteoporosis (osteanabrosis)
(3) Neurocentral deformation (cuneiform)
(4) Narrow intervertebral disk
(5) Asymmetry crush of intervertebral disk
(6) Unstable vertebra
(7) Osteophyte formation
(8) Separated image
(9) Sliding
(10) Other findings

(Reference)

Carry out the following motion function test, as necessary.

(1) Grasping power (2) Vertical jumping (3) Repeated jumping (4) Single leg standing with one eye closed

(5) Body forward bending while standing (6) $\mathrm{VO}_{2} \mathrm{max}$

\section{General Observation and Diagnosis:}


Appendix 3

Pre-Work Exercises

Sample 1 : Exercises Performed while Standing

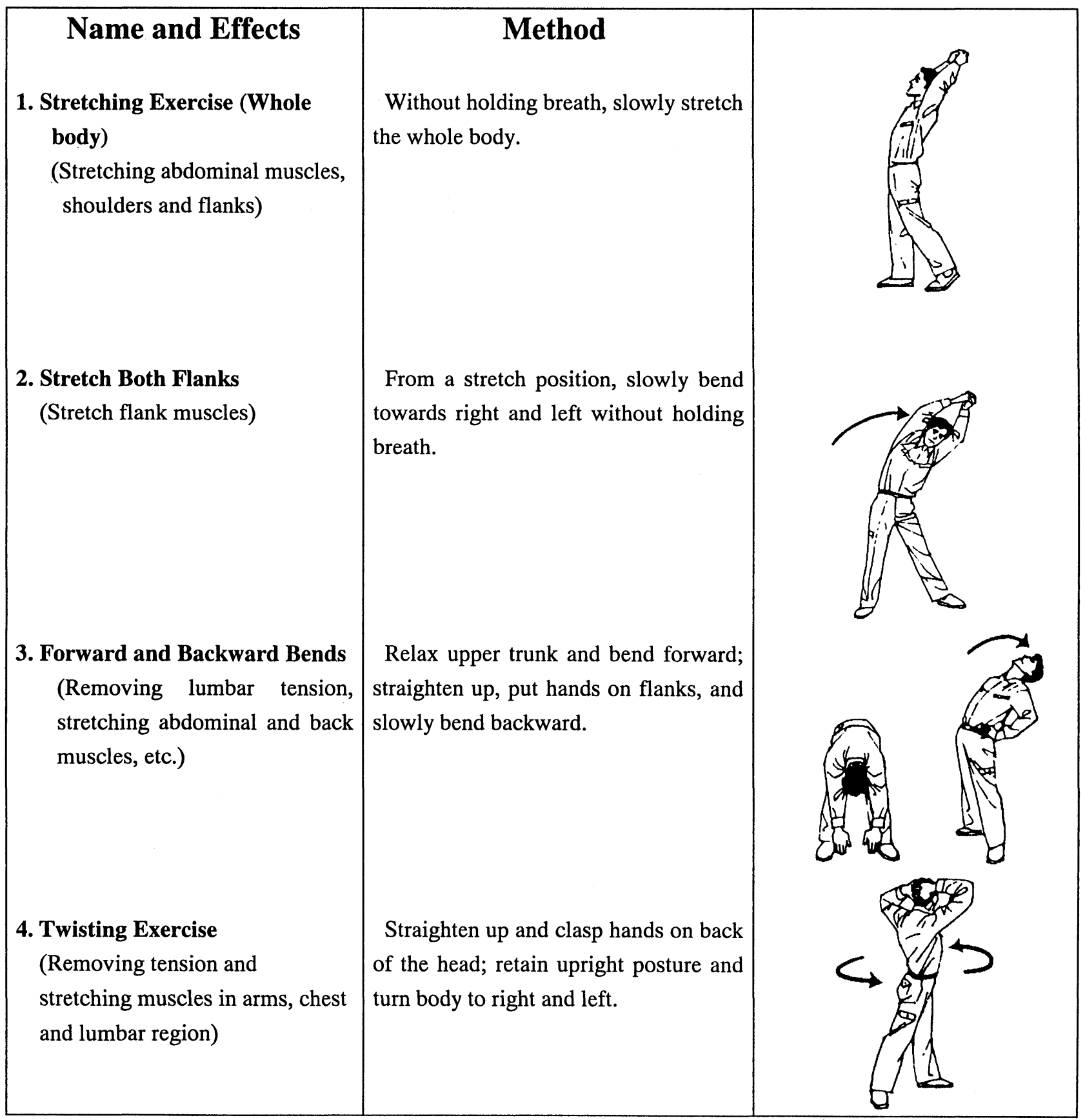




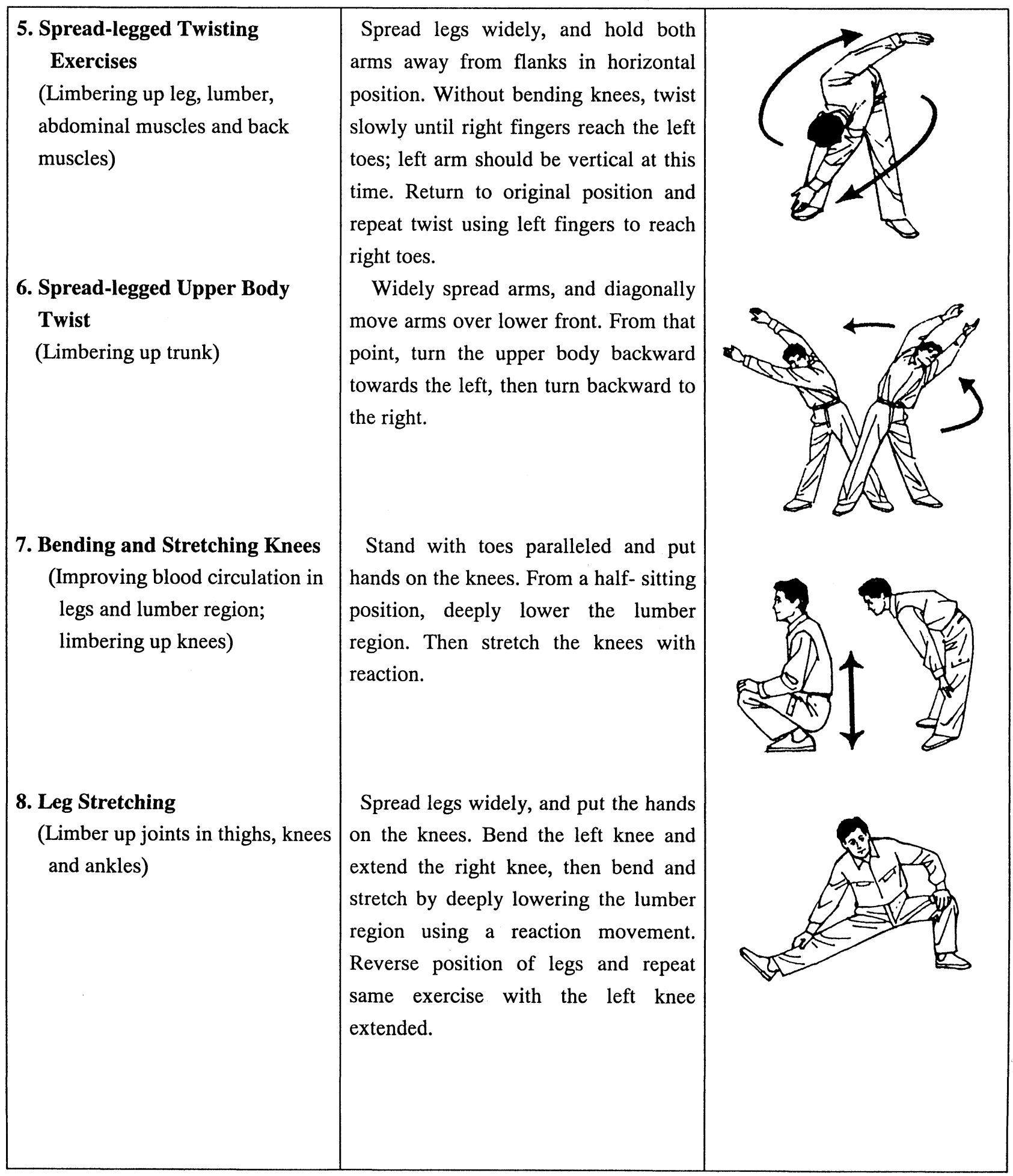




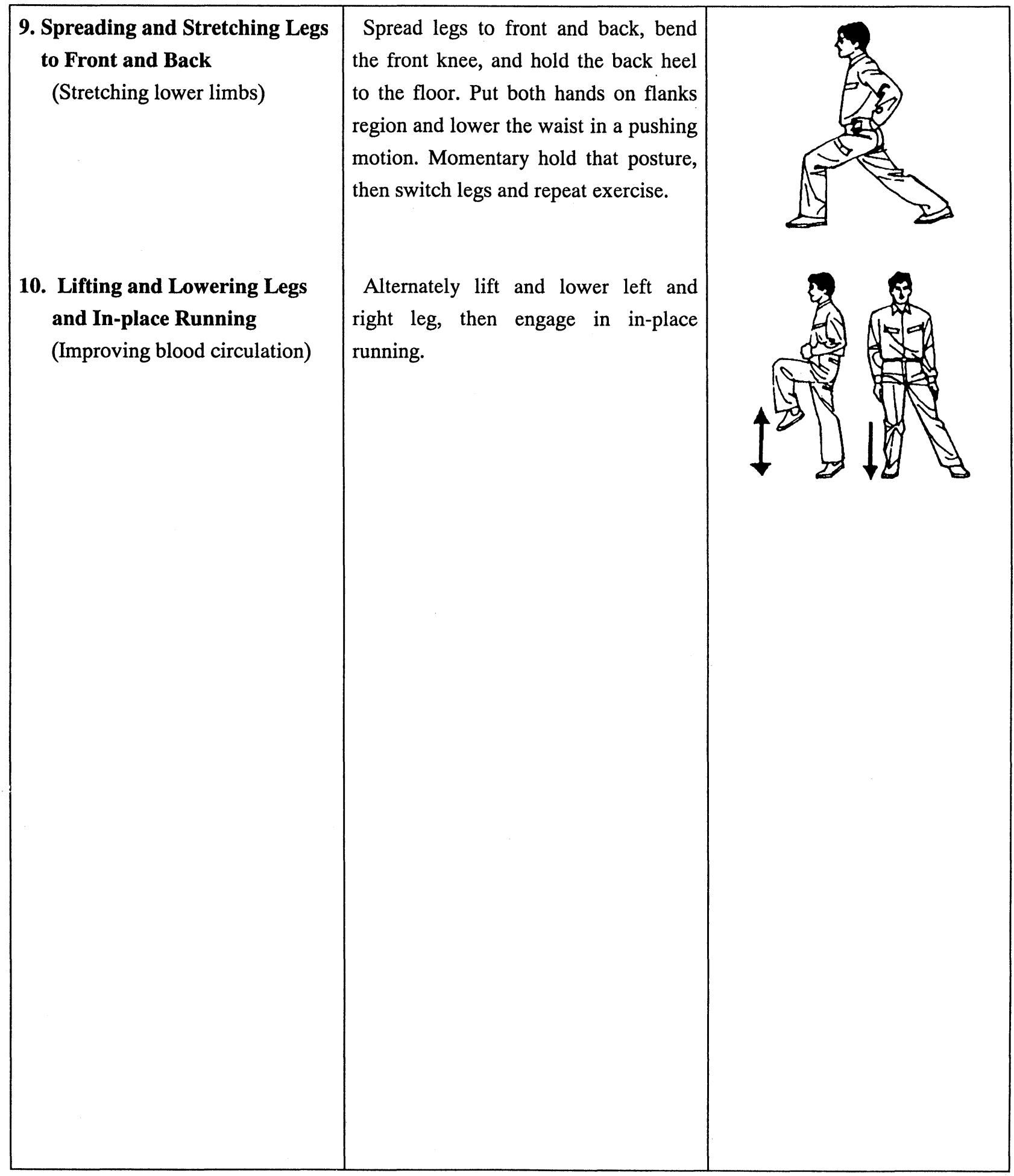


Sample 2 : Exercises Performed while Sitting in Chair

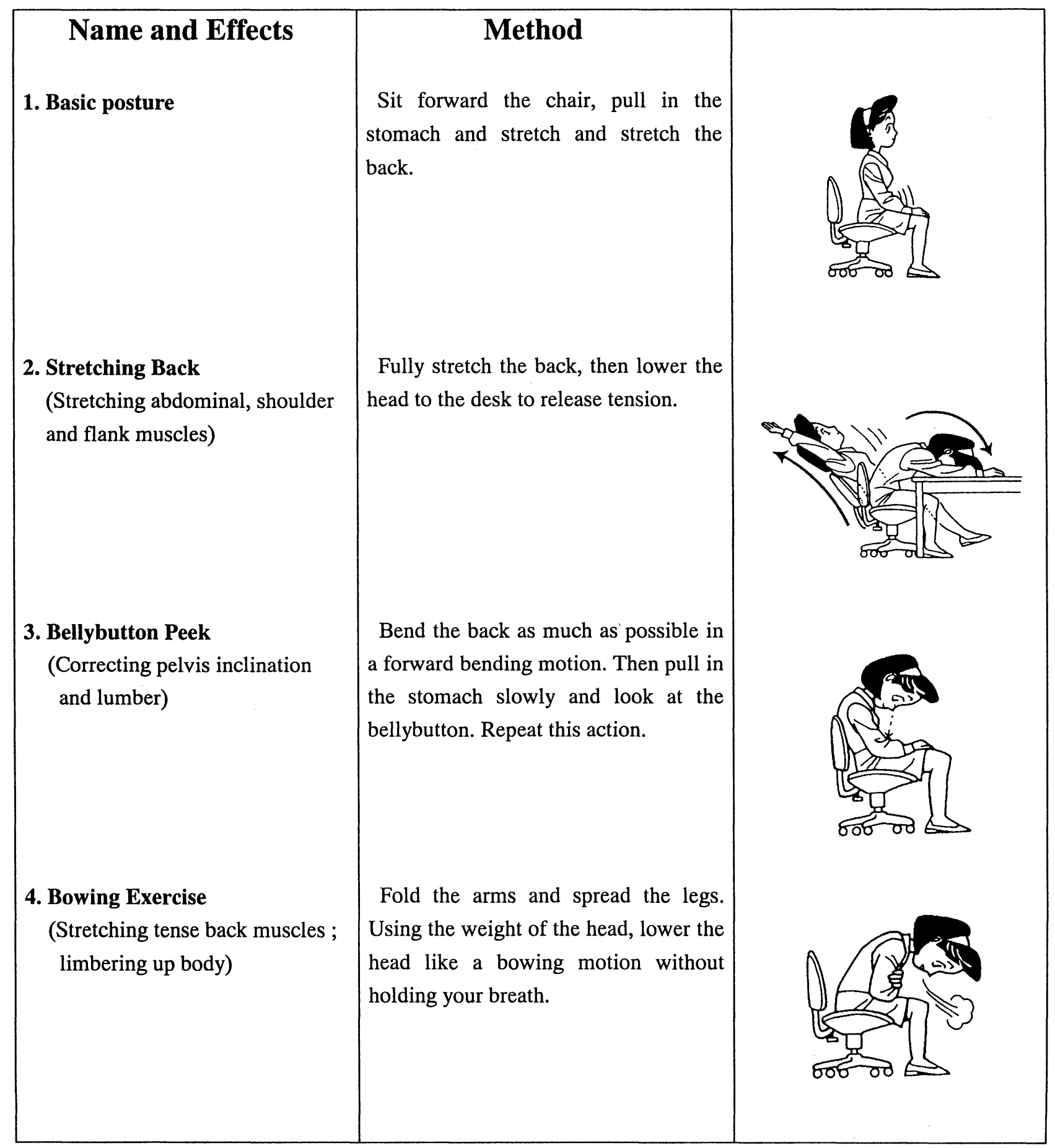




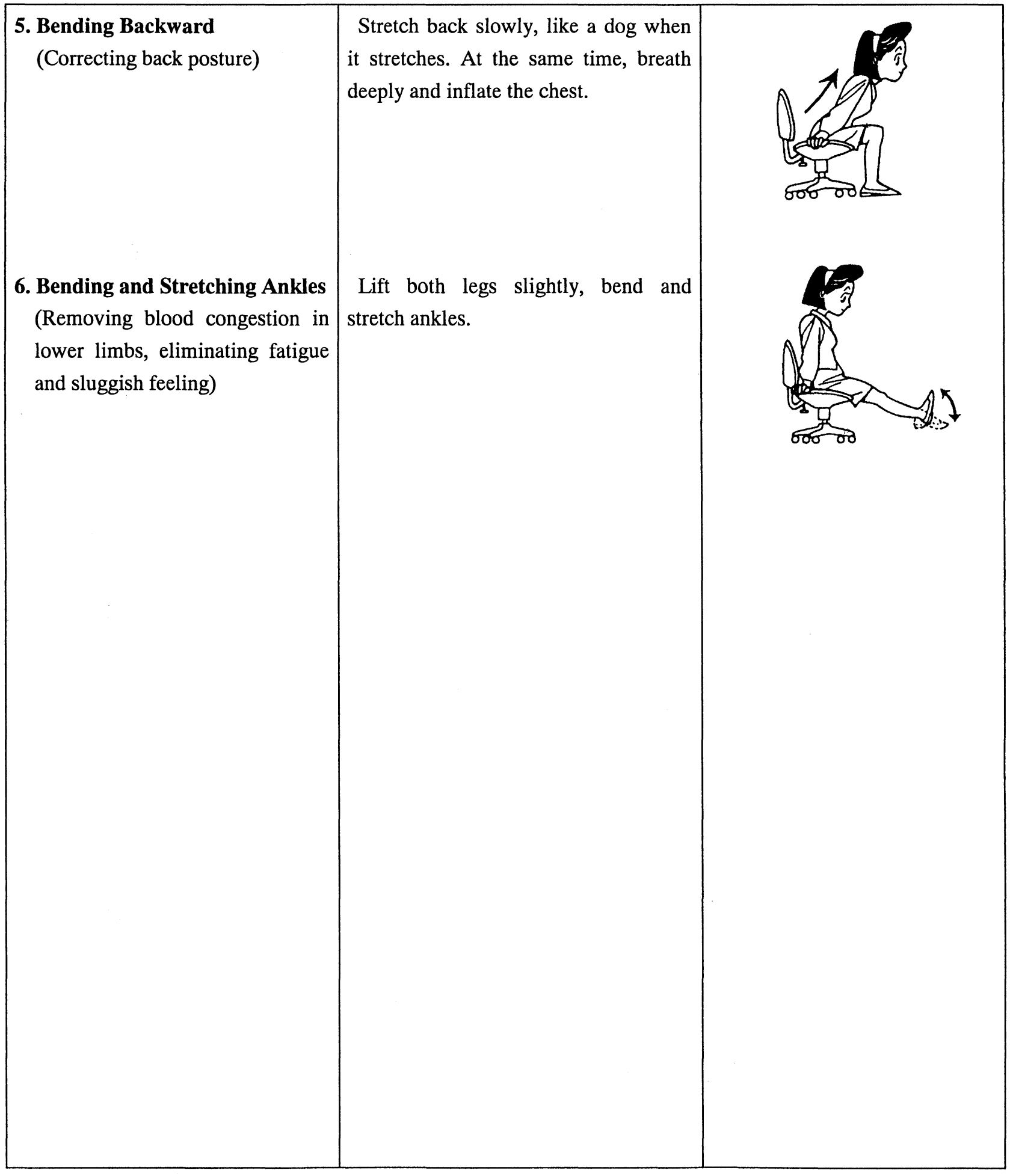


Example 3: Exercises Performed while on the Floor (Williams Exercise)

\begin{tabular}{|c|c|c|}
\hline Name and Effects & Method & \\
\hline $\begin{array}{l}\text { 1. Strengthening Abdominal } \\
\text { Muscles }\end{array}$ & $\begin{array}{l}\text { a. From a position on the back, bend } \\
\text { the knees with a little space between } \\
\text { the knees. } \\
\text { b. Stretch both arms and sit up slowly, } \\
\text { sliding the arms forward on the knees. } \\
\text { c. Turn back to Position a. }\end{array}$ & \\
\hline $\begin{array}{l}\text { 2. Strengthening Buttock } \\
\text { Muscles and Knee Flexor } \\
\text { Muscles } \\
\text { 3. Stretching Back }\end{array}$ & $\begin{array}{l}\text { a. From a position on the back, bend } \\
\text { the knees with a little space between } \\
\text { the knees. } \\
\text { b. Tighten the abdominal muscles and } \\
\text { push the lumbar vertebrae region to the } \\
\text { floor. Contract the muscles of the back } \\
\text { (above the lumbar vertebrae area), and } \\
\text { lift the buttocks from the floor. Do not } \\
\text { bend the back or lumbar region. } \\
\text { c. Turn back to Position a. } \\
\text { a. From a position on the back, bend } \\
\text { the knees with a little space between } \\
\text { the knees. } \\
\text { b. While bending both knees, bring } \\
\text { both knees to the chest and clasp the } \\
\text { arms around the knees. } \\
\text { c. Turn back to Position a. }\end{array}$ & \\
\hline
\end{tabular}




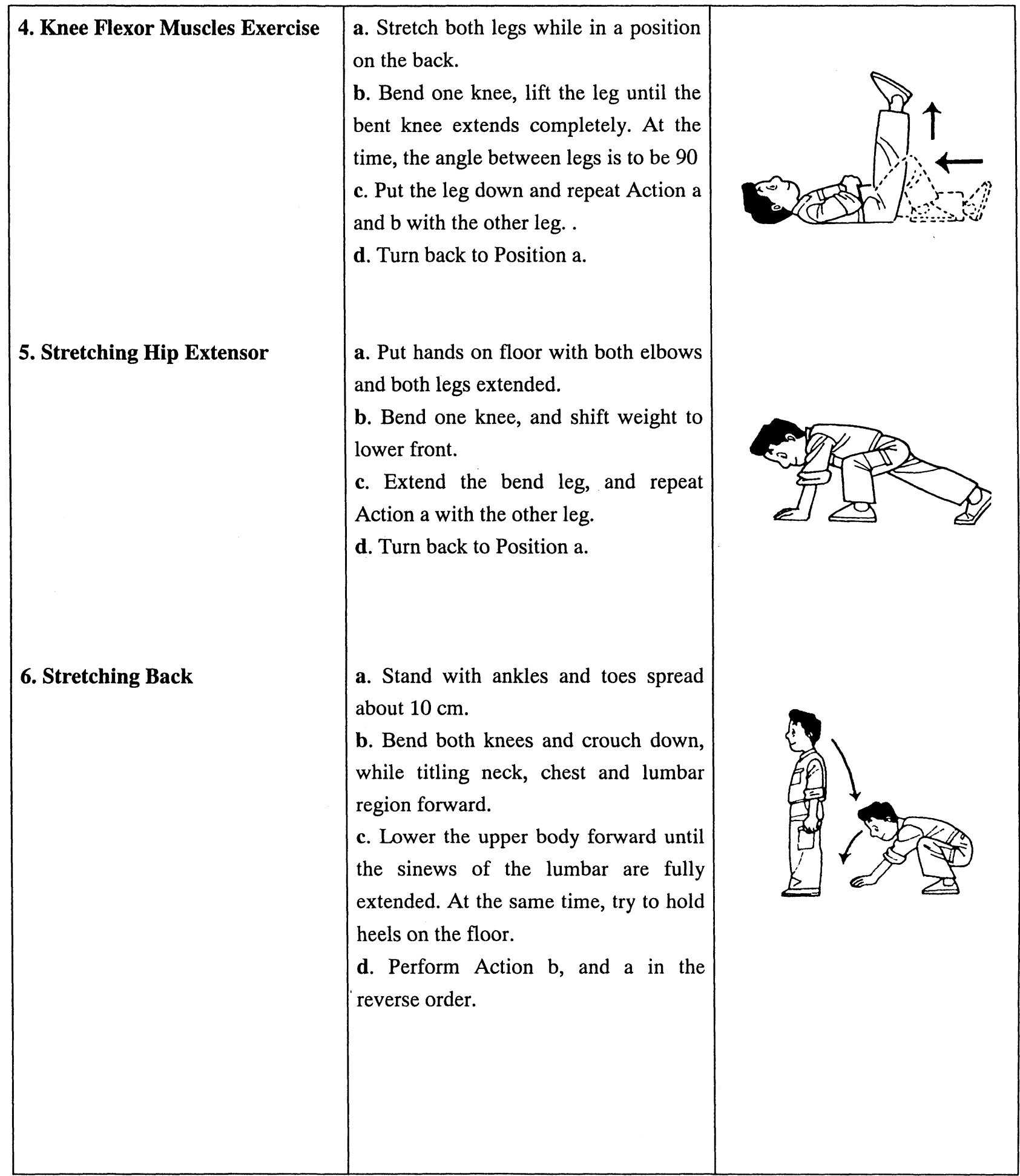


Appendix 4

Low Back Pain Prevention Exercises (Example)

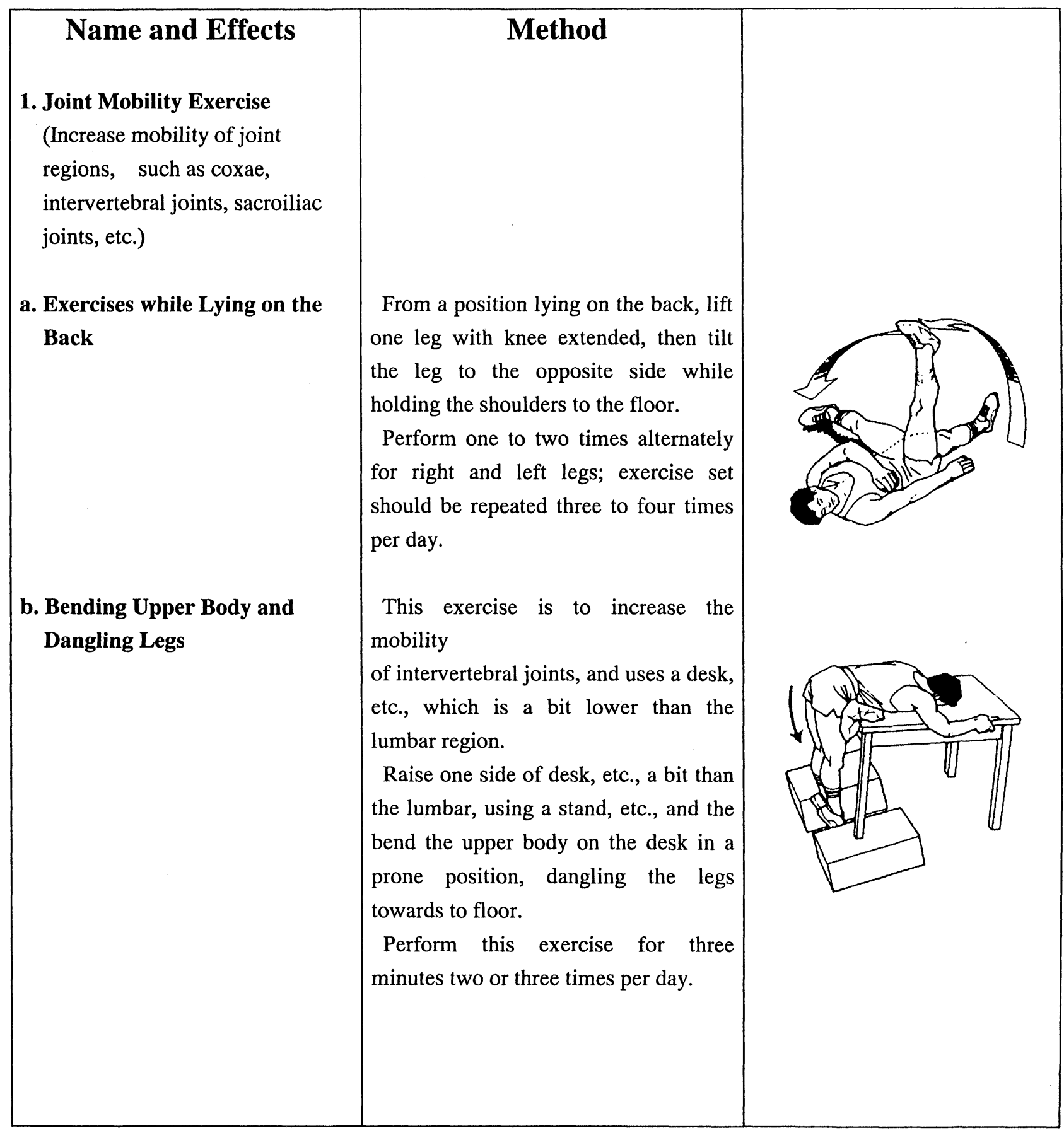




\section{Extending Ligaments of Soft}

Tissues

(Extending knee joint flexor

group and trunk rectus group)

a. Leg Crossing Exercise

b. Leg Lifts

\section{Muscle Rebuilding Exercise}

( Increase muscle strength in trunk buttocks and lower limbs)

\section{a. Exercise of Coccyx Lifting}

Stand with legs crossed and the front knee slightly bent. Extend the back knee, then bow. Change legs, and repeat the same.

Perform 10 times for each side ; repeat exercise set two or three times per day.

Lie on the back, and life one leg with knee extended. Perform 20 times for each side ; repeat exercise set two or three times per day.

This exercise strengthens the hip muscle group. Lie on the back, bend the knee, and lift the hip slightly.

Perform 20 times; repeat exercise set two times per day.
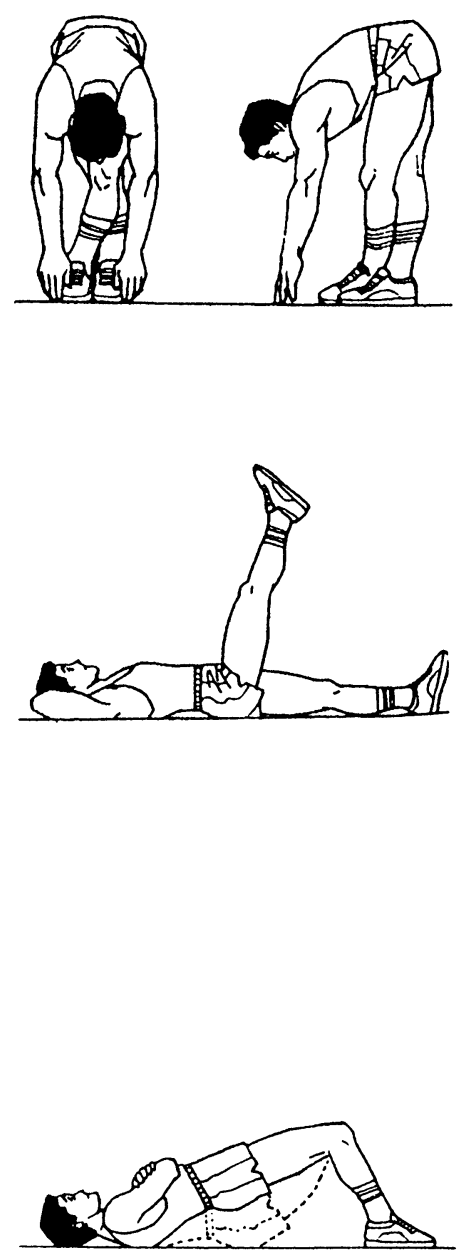


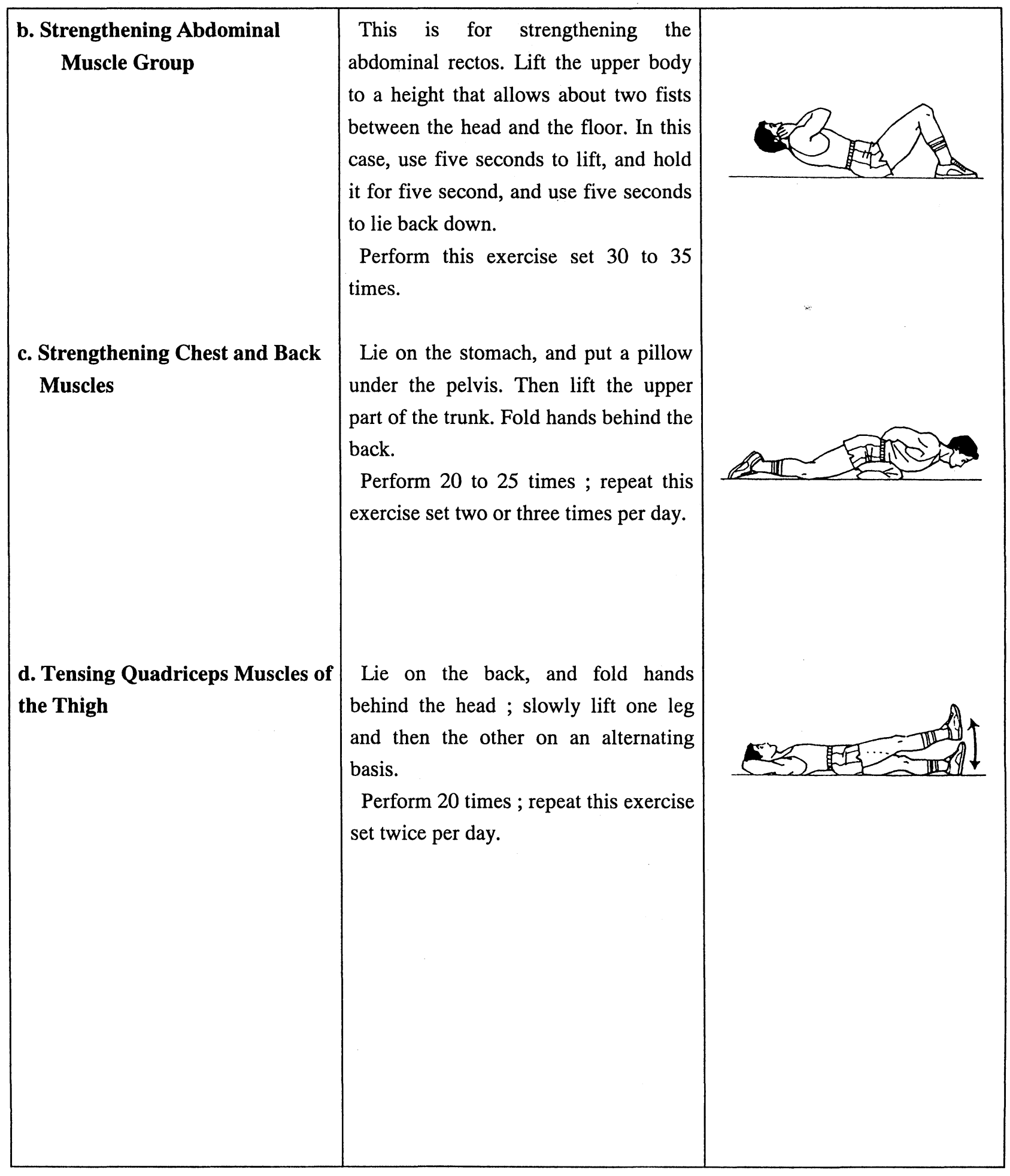

